\title{
Exaggerated Increases in Microglia Proliferation, Brain Inflammatory Response and Sickness Behaviour upon Lipopolysaccharide Stimulation in Non-Obese Diabetic Mice
}

\author{
Barry McGuiness $^{\mathrm{a}}$ Sinead M. Gibney ${ }^{\mathrm{a}}$ Wouter Beumer $^{\mathrm{a}}$ Marjan A. Versnel ${ }^{\mathrm{a}}$ \\ Inge Sillaber ${ }^{c}$ Andrew Harkin ${ }^{b}$ Hemmo A. Drexhage $^{a}$ \\ a Department of Immunology, Erasmus MC, Rotterdam, The Netherlands; ${ }^{\text {T }}$ Trinity College Institute of Neuroscience, \\ Trinity College, Dublin, Ireland; ' Affectis Pharmaceuticals AG, Dortmund, Germany
}

\section{Key Words}

Non-obese diabetic mouse - Microglia inflammation .

Growth factor · Lipopolysaccharide

\begin{abstract}
The non-obese diabetic (NOD) mouse, an established model for autoimmune diabetes, shows an exaggerated reaction of pancreas macrophages to inflammatory stimuli. NOD mice also display anxiety when immune-stimulated. Chronic mild brain inflammation and a pro-inflammatory microglial activation is critical in psychiatric behaviour. Objective: To explore brain/microglial activation and behaviour in NOD mice at steady state and after systemic lipopolysaccharide (LPS) injection. Methods: Affymetrix analysis on purified microglia of pre-diabetic NOD mice (8-10 weeks) and control mice (C57BL/6 and CD1 mice, the parental non-autoimmune strain) at steady state and after systemic LPS $(100 \mu \mathrm{g} / \mathrm{kg})$ administration. Quantitative PCR was performed on the hypothalamus for immune activation markers (IL-1 $\beta$, IFN $\gamma$ and TNFa) and growth factors (BDNF and PDGF). Behavioural profiling of NOD, CD1, BALB/C and C57BL/6 mice at steady state was conducted and sickness behaviour/anxiety in NOD and CD1 mice was monitored before and after LPS injection. Results: Genome analysis revealed cell cycle/cell death and
\end{abstract}

\section{KARGER}

E-Mail karger@karger.com www.karger.com/nim

\section{The Author(s) \\ Published by S. Karger AG, Basel 1021-7401/16/0233-0137\$39.50/0 \\ This article is licensed under the Creative Commons Attribution-} NonCommercial-NoDerivatives 4.0 International License (CC BYNC-ND) (http://www.karger.com/Services/OpenAccessLicense) Usage and distribution for commercial purposes as well as any distribution of modified material requires written permission. survival aberrancies of NOD microglia, substantiated as higher proliferation on BrdU staining. Inflammation signs were absent. NOD mice had a hyper-reactive response to novel environments with some signs of anxiety. LPS injection induced a higher expression of microglial activation markers, a higher brain pro-inflammatory set point (IFNY, IDO) and a reduced expression of BDNF and PDGF after immune stimulation in NOD mice. NOD mice displayed exaggerated and prolonged sickness behaviour after LPS administration. Conclusion: After stimulation with LPS, NOD mice display an increased microglial proliferation and an exaggerated inflammatory brain response with reduced BDNF and PDGF expression and increased sickness behaviour as compared to controls.

(c) 2016 The Author(s)

Published by S. Karger AG, Basel

\section{Introduction}

The non-obese diabetic (NOD) mouse, derived from the CD1 mouse, displays spontaneous development of autoimmune thyroiditis and type 1 diabetes, similar to what is observed in humans [1]. The autoimmune pheno-

B.M., S.M.G., A.H. and H.A.D. contributed equally to this paper.

Prof. Hemmo A. Drexhage

Department of Immunology, Na1105, Erasmus MC

's Gravendijkwal 230

NL-3015 CE Rotterdam (The Netherlands)

E-Mail h.drexhage@erasmusmc.nl 
type found in NOD mice is mediated by T cell infiltration of the endocrine glands and destruction of the endocrine cells by these autoreactive lymphocytes [2]. Inborn and pre-existing aberrancies in macrophages, dendritic cells and their precursors present in the endocrine glands have been shown to play a crucial role in the early stages of autoreactive T cell stimulation at the onset of endocrine autoimmune diseases [3-9]. These include an aberrant growth rate and an aberrant differentiation of the cells from precursors, leading to a progeny of cells with a reduced growth factor production for neighbouring endocrine cells [10] and a deficient capability to induce immune tolerance to auto-antigens $[8,10,11]$. Moreover, upon stimulation with an environmental or endogenous inflammatory stimulus, such as lipopolysaccharide (LPS) or apoptotic cells, these abnormally differentiated local macrophages and dendritic cells show an exaggerated inflammatory response characterised by an increased secretion of pro-inflammatory cytokines, such as TNFa, IL- $1 \beta$ and iNOS $[10,12]$.

Interestingly, there is a higher prevalence of major mood disorders in autoimmune thyroiditis and type 1 diabetes patients. Evidence suggests that patients with autoimmune thyroiditis and type 1 diabetes are up to 3 times more likely to present with a major mood disorder than the general population, and vice versa [13-18]. Of note, there is also limited evidence in the NOD mouse model that the increased diathesis of the animal for autoimmune thyroiditis/insulitis is associated with abnormal behaviour, such as increased locomotion in the open field and reduced social exploration, locomotion and rearing after IL-1 injection. This behaviour can be considered as an anxiety response to immune stimulation $[19,20]$.

While there is thus ample evidence that deregulated interactions of local aberrant macrophages/dendritic cells and $\mathrm{T}$ cells form the cornerstone of the immune pathogenesis of autoimmune thyroiditis and type 1 diabetes, there is a lack of understanding of the immune pathogenesis of major mood disorders. Nevertheless, increasing evidence suggests that chronic mild inflammation of the brain may play a critical role in their development. A link between pro-inflammatory monocyte activation, microglial activation and mood disorders has been shown, at least in a subset of patients [21-25].

The question thus arises whether the NOD mouse apart from being a model of autoimmune thyroiditis/insulitis - might also be an animal model for mood disorders with inflammatory activated microglia and signs of chronic mild inflammation in the brain.
Here, we study the Affymetrix gene expression of FACS-purified microglia of NOD mice, the gene expression of a set of inflammatory markers in the whole brain (hypothalamus) of NOD mice and the behaviour of these mice (using various behavioural paradigms) in comparison to CD1 mice (the non-autoimmune ancestral strain of NOD mice) and in a set of experiments with C57BL/6 and $\mathrm{Balb} / \mathrm{C}$ mice). We studied, in particular, the gene expression of a panel of well-known and undisputed proinflammatory markers (TNFa, IL-1 $\beta$, IL6, IFN $\gamma$ and IDO) in the microglia and hypothalamus tissue of the mice. We chose to study the hypothalamus of the mice as a sample of whole-brain tissue for practical reasons, and other parts of the brain were used for the purification of microglia. Earlier extensive studies have been performed on the hypothalamus in relation to inflammation [26,27], and immune stimulation is known to alter the expression of stress related genes in the hypothalamus [28].

Pro-inflammatory activation of myeloid cells including microglia is easily induced by LPS, with concomitant rises in pro-inflammatory cytokines like IL- 6, IL- $1 \beta$ and TNFa. It has previously been reported that systemic administration of LPS to experimental animals induces transient, short-term sickness behaviour, followed by the delayed $(>24 \mathrm{~h}$ ) presence of depressive behaviours which persist in the absence of sickness behaviour [29]. Furthermore, mice administered with LPS were reported to have prolonged activated microglia for up to 3 days following treatment accompanied by depressive behaviours [30].

Increases in pro-inflammatory cytokines, but also reductions in growth factors such as BDNF, have been reported in the brain of rodents systemically challenged with LPS [31, 32]. Moreover, previous work by our group in the maternal inflammation model showed that LPS induced foetal microglial inflammatory activation, but also pronounced reductions in foetal microglial genes involved in nervous system development and function, particularly neurite growth and formation [33]. A role for other growth factors in the pathogenesis of mood disorders has also been suggested, including a role for PDGF, which has been shown to be altered in the serum of psychiatric patients [34]. We have reported on abnormal serum levels of BDNF and PDGF in patients prone to mood disorders and thyroid autoimmunity $[35,36]$.

The second aim of this study was to explore whether there is LPS-induced, altered inflammatory and growth factor pathway activation in the microglia and hypothalamus of NOD mice in comparison to the CD1 strain. We explored the gene expression of a panel of pro-inflamma- 
tory markers (TNF $\alpha$, IL-1 $\beta$, IL6, IFN $\gamma$ and IDO) and the 2 important growth factors for neuron development related to psychiatric disease, BDNF and PDGF. We re-explored whether LPS induced altered behaviour in the NOD mouse compared to the CD1 strain.

\section{Methods}

\section{Animals}

In the Affectis laboratory, studies focused on behavioural profiling of multiple strains of mice, including male NOD/ShiLtJ (Eramsus MC), CD1 (Harlan), C57BL/6J (Harlan) and Balb/c (Harlan) mice. Mice were studied at 10 weeks of age. In parallel studies, microglial gene profiling and proliferation via BrdU staining were carried out at Erasmus MC in female NOD/ShiLtJ (Erasmus MC) and C57BL/6 (Charles River) 8-10 weeks of age.

In the Trinity laboratory, studies focused on LPS stimulation, behaviour and microglial gene profiling before and after LPS administration and markers of brain inflammation in the hypothalamus (in collaboration with Erasmus MC). For these studies, female NOD/ShiLtJ and CD-1 mice were obtained from Charles River and Harlan, respectively, at 8-10 weeks of age.

All mice were group-housed and maintained on a 12-hour light/dark cycle in a temperature-controlled room $\left(22 \pm 2^{\circ} \mathrm{C}\right)$. Food and water were available ad libitum. The experimental protocols were in compliance with the European Communities Council directive (86/609/EEC).

NOD mice of the Erasmus MC and Charles River laboratories have an incidence of diabetes at 20 weeks of age in $80 \%$ of females and $40-60 \%$ of males, starting in females at about 12 weeks of age and several weeks later in males.

However, it is important to note that all experiments were carried out on the NOD mice in a pre-diabetic state. In the Results section, the normal glucose levels in blood from 1 experiment are shown but, in all instances, the mice in the experiments were normoglycemic (both in the blood and urine tests).

\section{LPS Administration}

To evaluate the effect of LPS, NOD mice (Trinity, Erasmus $\mathrm{MC}$ ), CD1 mice (Trinity, Erasmus MC) and C57BL/6J (Erasmus MC) received an intraperitoneal (i.p.) injection of LPS (100 $\mu \mathrm{g} / \mathrm{kg})$ prepared from Escherichia coli (Sigma) or an i.p. injection of saline $4 \mathrm{~h}$ or $24 \mathrm{~h}$ before euthanisation.

\section{Microglia Isolation}

Microglia were isolated according to a modified version of the method described previously [37]. In short, the mice were perfused with PBS after blood sampling by cardiac puncture. Subsequently, the brains were removed and stored in ice-cold $1 \times$ Hank's balanced salt solution (HBSS, Gibco), containing $15 \mathrm{~mm}$ HEPES (Gibco) and 0.5\% glucose (Sigma). The brains were cut into small pieces, dissociated in a glass tissue homogenizer (VWR, Amsterdam, The Netherlands) and tritruated by firepolished glass Pasteur pipettes (VWR). The single-cell suspension was first filtered with a $70-\mu \mathrm{m}$ cell strainer (Becton Dickinson) and pelleted for $10 \mathrm{~min}$ at $200 \mathrm{~g}$ and $4^{\circ} \mathrm{C}$. A $100 \%$ Percoll stock (GE Healthcare) was made using 9 volumes of Percoll and

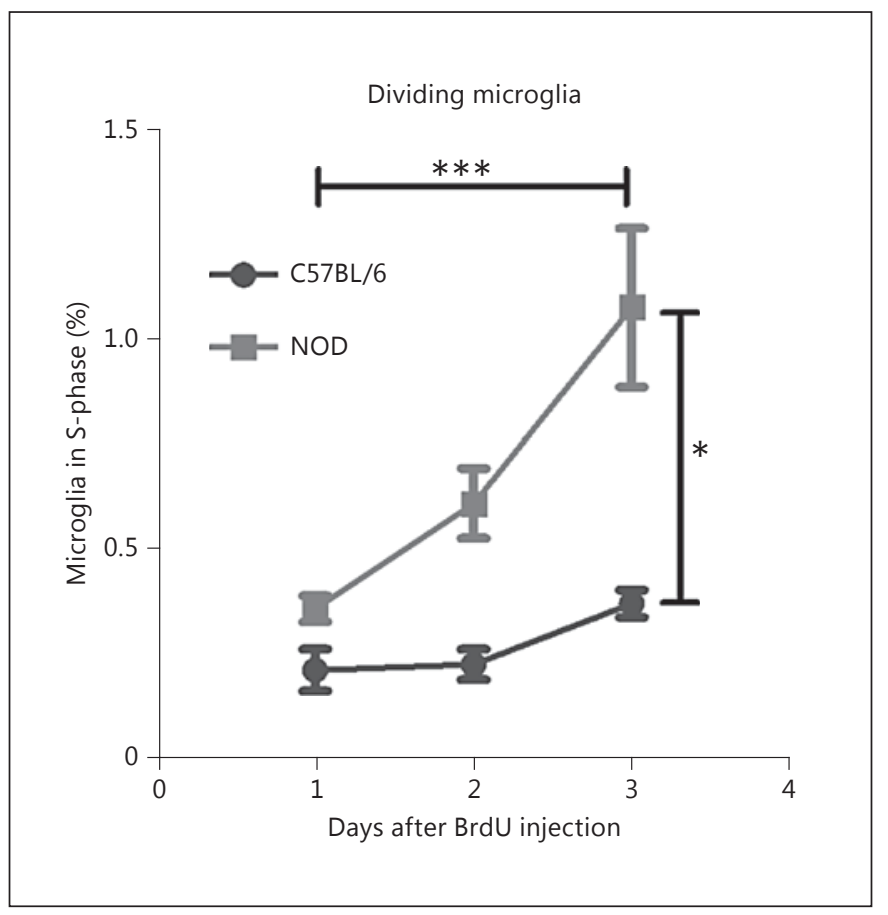

Fig. 1. Use of the proliferation marker BrdU revealed a higher percentage of microglia in the DNA-replicating S-phase 3 days after BrdU administration when compared to CD1 controls. Data expressed as mean \pm SEM, $\mathrm{n}=3$ per group. ${ }^{*} \mathrm{p}<0.05,{ }^{* * *} \mathrm{p}<0.001$.

1 volume of HBSS $10 \times$. The $100 \%$ Percoll stock was diluted by adding $1 \times$ Dulbecco's PBS (DPBS, Gibco) in order to obtain 75 and 25\% Percoll stocks. The cell pellet was taken up in $10 \mathrm{ml} 75 \%$ Percoll stock and overlayed with $10 \mathrm{ml}$ of $25 \%$ Percoll stock and $6 \mathrm{ml}$ of DPBS (0\% Percoll), respectively. The density gradient was centrifuged in a swinging bucket rotor at $800 \mathrm{~g}$ (slow acceleration without brake) for $30 \mathrm{~min}$ at $4^{\circ} \mathrm{C}$. After centrifugation, a thick myelin-containing layer at the $0 / 25 \%$ Percoll interface was discarded and the cells between the $25 / 75 \%$ interfaces were collected and washed in $30 \mathrm{ml}$ of ice-cold DPBS. The cells were resuspended in DPBS containing $0.1 \%$ BSA and labelled with CD11b-APC (Becton Dickinson) and CD45-PB (Biolegend) antibodies. Cells were washed and $S S C^{\text {low }} \mathrm{CD} 11 \mathrm{~b}^{+} \mathrm{CD} 45^{\text {low }}$ microglia were sorted in DPBS $+0.1 \%$ BSA on a MoFlo FACS sorter (Dako). Re-analysis of the sorted cells indicated a purity of $>99 \%$. Finally, cells were washed and lysed in extraction buffer and stored at $-80^{\circ} \mathrm{C}$ until RNA isolation.

\section{Bromodeoxyuridine Investigation}

Investigation into the amount of dividing microglia in CD1 and NOD mice was carried out according to the manufacturer's instructions (BD). In brief, $1 \mathrm{mg}$ bromodeoxyuridine (BrdU) was injected i.p. and the mice were euthanised 1, 2 and 3 days after BrdU administration. The microglia were isolated as above. Any BrdU present within these microglia was stained for with antiBrdU fluorescent labels and read via flow cytometry. 
RNA Isolation and Amplification, Affymetrix Microarrays and Quantitative PCR

RNA was isolated with the PicoPure kit (Arcturus, Applied Biosystems) according to the manufacturer's protocol, including a DNase I treatment (Qiagen, Venlo, The Netherlands) to remove genomic DNA contamination. The RNA was reverse-transcribed, amplified, biotinylated and fragmented with the Ovation Pico WTA v2 and Encore Biotin Module (NuGEN Technologies, Leek, The Netherlands) and subsequently hybridized on Mouse Genome 4302.0 arrays (Affymetrix, High Wycombe, UK) according to the manufacturer's protocols.

\section{Microarray Analysis}

Quality analysis of the CEL data was assessed by running a standardized workflow developed at the BiGCaT department of Maastricht University, The Netherlands (http://www.arrayanalysis. org/). The expression data containing CEL files were imported and processed further with BRB-Arraytools (R. Simon, http://linus.nci. nih.gov/BRB-ArrayTools.html). Gene expression data were normalized using RMA (Robust Multichip Average) [38]. A list of differentially expressed genes in the 2 classes was identified by using a multivariate permutation test, using the class comparison tool in BRB-ArrayTools. Ingenuity pathway analysis (Ingenuity ${ }^{\circledR}$ Systems, www.ingenuity.com) was used for annotation and to sort data relevant to fold changes. Gene expression was considered statistically significantly different when $\mathrm{p}<0.05$. Final fold-change information provided by the program did not contain the standard error of the mean, and so we did not include it; however, all data pertain to groups of 3 mice. $\mathrm{p}<0.05$ was significant.

Analysis of Hypothalamic Gene Expression by Real-Time PCR RNA was extracted from hypothalamic tissue using the NucleoSpin ${ }^{\circledR}$ RNA II total RNA isolation kit (Macherey-Nagel, Germany). Genomic DNA contamination was removed by the addition of DNase to the samples. RNA was reverse-transcribed into cDNA using a high-capacity cDNA archive kit (Applied Biosystems, Darmstadt, Germany). Real-time PCR was performed using an ABI Prism 7300 instrument (Applied Biosystems) as previously described [39]. Taqman Gene Expression Assays (Applied Biosystems) containing forward and reverse primers and an FAM-labelled MGB Taqman probe were used to quantify each gene of interest. Assay IDs for the genes examined were as follows: IL-1 $\beta$ (Mm01336189_m1), IL-6 (Mm00446190_m1), TNFa (Mm00443258_m1), IFN $\gamma$ (Mm00801778_m1), IDO (Mm00492586_m1), PDGF (Mm00440677_m1), BDNF (Mm04230607_m1) and FGF2 (Mm00433287_m1). PCR was performed using Taqman ${ }^{\circledR}$ Universal PCR master mix and samples were run in duplicate. The cycling conditions consisted of $90^{\circ} \mathrm{C}$ for $10 \mathrm{~min}$ and 40 cycles of $90^{\circ} \mathrm{C}$ for $15 \mathrm{~s}$ followed by $60^{\circ} \mathrm{C}$ for $1 \mathrm{~min}$. $\beta$-Actin was used as an endogenous control to normalize gene expression data. Relative gene expression was calculated using the $\Delta \Delta \mathrm{CT}$ method with Applied BioSystems RQ software (Applied BioSystems, UK).

\section{Behavioural Testing}

Open-Field Test (Affectis, Trinity)

Mice were placed in the centre of a square arena $(30 \times 30 \mathrm{~cm})$ in a dimly lit room. Movement in the arena was monitored over a period of $30 \mathrm{~min}$, after which point, the mice were returned to the home cage. The trials were conducted between 8:00 a.m. and 12:30 p.m.
Modified Hole Board (Affectis)

As described before in detail [40], mice were habituated to oat flakes prior to testing, with a piece of almond representing the novel food. Mice were placed in the outer area of the test apparatus facing the board. Movement, food consumption and exploration were among the behaviours scored during a 5-min test period. The trials were conducted between 8:00 a.m. and 12:30 p.m.

\section{Long-Term Monitoring of Home Cage Activity (Affectis,} Trinity)

As previously described [41], mouse activity was monitored in the home cage over a period of $24 \mathrm{~h}\left(\mathrm{t}_{0}=\right.$ beginning of the dark phase). Parameters such as locomotor activity, rearing and climbing behaviours were determined in a side-view using small CCD cameras and the ANY-maze software.

\section{Novelty-Induced Hypophagia (Affectis)}

Mice were presented with diluted, sweetened, condensed milk (1:3 milk + water: $0.2 \%$ saccharin) for $30 \mathrm{~min}$ for 3 consecutive days as part of a training regime in their home cage. On day 4 , the solution was presented again to the mice in their home cage, with the total fluid consumption and latency to the first drink being measured. On day 5 , the mice were placed in a novel cage without bedding and under a bright light and presented with the sweetened milk again. Latency and total fluid intake were measured again. The trials were conducted between 8:00 a.m. and 12:30 p.m.

\section{Forced-Swim Test (Affectis)}

As described in detail by Sillaber et al. [40], the mice were placed in a beaker $(12 \mathrm{~cm}$ in diameter and $24 \mathrm{~cm}$ in height) filled with water $\left(25-26^{\circ} \mathrm{C}\right)$ to a height of $12 \mathrm{~cm}$. The animals were tested for a period of $5 \mathrm{~min}$ and then removed, dried and returned to their home cage for $24 \mathrm{~h}$. They were then exposed for a second time. Immobility time was calculated by a trained observer. The trials were conducted between 8:00 a.m. and 12:30 p.m.

\section{Tail Suspension Test (Trinity)}

The tail suspension test (TST) is an inescapable stress that measures the presence of despair behaviour in the mice subjected to it. Mice are attached by their tails to a wire affixed to the horizontal bar of a retort stand so that they are suspended $25 \mathrm{~cm}$ above the base of the stand. The mice are left in suspension upside down for a period of $6 \mathrm{~min}$, the last $5 \mathrm{~min}$ of which are scored for immobility. Their behaviour was scored by a trained, blinded observer.

\section{Behavioural Tests before and after LPS Stimulation}

In order to monitor the behavioural response of the mice to an immune stimulus, the activity in a novel home cage was monitored following LPS administration. These experiments were carried out in the Trinity laboratory. Animals were individually placed in activity monitor cages measuring $32 \times 20 \times 18 \mathrm{~cm}$ (length $\times$ width $\times$ height). These cages were connected to an AM1051 data logger (Benwick Electronics). Each cage contained 2 sets of horizontal infrared beams, at 3 and $6 \mathrm{~cm}$ from the bottom of the cage, respectively. Each set consisted of a $12 \times 7$ beam matrix, which formed a grid of $66 \times 2.54 \mathrm{~cm}^{2}$ cells in each cage. Together, the beams and data logger recorded activity and rearing. Activity was determined by the number of times a beam was broken and was measured from when the beam was first broken until no beam had been broken for $5 \mathrm{~s}$. Data were analysed using the total number of beam breaks 
over the 30-min trial. The trials were conducted between 10 a.m. and 2 p.m. This protocol was carried out both before the immunological challenge (with LPS), in order to determine the baseline levels of locomotor and rearing activity, and then 4 and $24 \mathrm{~h}$ after LPS injection.

Statistical Analysis of Data

All values are expressed as mean \pm standard error of the mean (SEM). Data were analysed using either a Student t test or a twoway ANOVA followed by the Newman-Keuls post hoc test or the Fisher LSD post hoc test (GB stat). A value of $\mathrm{p}<0.05$ was considered to be statistically significant.

\section{Results}

Analysis of Microglial Genome Point to an Abnormal Cell Cycle and Proliferation at Steady State and after LPS Administration

When examining the expressional profile of NOD, C57BL/ 6 and CD1 mice, a non-biased approach was first selected. Differentially expressed genes of isolated microglia were analysed via the Ingenuity software to identify the top-rated 'Molecular and Cellular Functions', which revealed that cell death, cell survival, cell cycle and gene expression listed in the top 5-most changed cell functions in NOD microglial cells when compared to both CD1 and C57BL/6 mice (see online suppl. table 1, www.karger.com/doi/10.1159/000446370).

Since isolated microglia from NOD mice were showing greater gene expression of molecules related to cell death, cell survival and cell cycle compared to the 2 independent strains of mice, Erasmus MC further investigated microglial survival and proliferation within the brain in a set of experiments in which the C5BL/6J mouse strain was used as a control. Tests utilising the cell-dividing marker BrdU revealed that NOD mice had a greater number of microglia in the S-phase of the cell cycle on day 3 following BrdU administration than the C5BL/6J mouse strain (fig. 1).

Ingenuity analysis of microglial Affymetrix genome expression after LPS injection also revealed that the main differences in cellular functions between NOD and control mice were related to cell cycle and cell survival (see online suppl. table 1 for this comparison).

It is worthy of note that in the ingenuity analysis, functions or pathways related to inflammation or a high immune activity were not different in the NOD and the control strains.

\section{Inflammatory Factor Profile and Response to LPS}

Following on from the above non-biased observations, a more focused approach was carried out to investigate the inflammatory response of microglia and a sample of whole-brain tissue (hypothalamus) in NOD versus CD1 mice.

Quantities of microglia cells were estimated by the mRNA expression of the microglial markers CD68 and $\mathrm{CD} 11 \mathrm{~b}$ in whole-brain tissue (i.e. the hypothalamus). These markers did not differ between NOD and CD1 mice at steady state, but following LPS administration, a $2 \times$ higher level of these microglial markers was present in both mouse strains (and did not differ between strains; data not shown).

To examine the immune profile of NOD and the parental CD1 strain, expression levels of several pro-inflammatory cytokines/compounds were measured, including TNF $\alpha$, IL-1 $\beta$, IL-6, IFN $\gamma$ and IDO. At steady state, differences in the expression levels of these inflammatory genes were not found between NOD and CD1 mice in either microglia (genome analysis) or whole-brain tissue (quantitative PCR, qPCR).

However, most of these inflammatory genes were induced by LPS in the microglia and whole-brain tissue and expression was often stronger in the NOD mice than in the CD1 mice, although only 2 of them displayed significant strain-dependent differences in expression levels after LPS injection. Firstly, in response to LPS, a significant increase in IL- $1 \beta$ was found in the NOD mouse $4 \mathrm{~h}$ after injection in the whole-brain tissue. While LPS did induce an increase in IL-1 $\beta$ in the CD1 mice at this time point, the post hoc analysis revealed that this increase was not significant (fig. 2b). A large increase was also observed in IL-1 $\beta$ mRNA expression in isolated microglia of both strains. Secondly, when the expression of IFN $\gamma$ was measured, a significant effect of LPS was found in the NOD mouse. While no effect of LPS was found in the CD1 mouse, a 14 -fold increase in IFN $\gamma$ mRNA was found in the NOD mouse at $4 \mathrm{~h}$ after LPS stimulation when compared to its relative control $(p<0.05)$. Investigation of the isolated microglia showed no expression of IFN $\gamma$ in the CD1 mice whereas in NOD mice, it was actually increased, though non-significantly, following LPS administration. The expression of IDO, a gene shown to be induced by IFN $\gamma$, also showed a greater increase in the NOD mice following LPS administration when compared to the CD1 strain $(\mathrm{p}<0.05)$. However, primers for this gene were not present on the microarray chip used and, as such, IDO expression could not be investigated in isolated microglia.

Further investigation of microglial activation in the sample of whole-brain tissue revealed that NOD mice had significantly higher elevations of the costimulatory mark- 


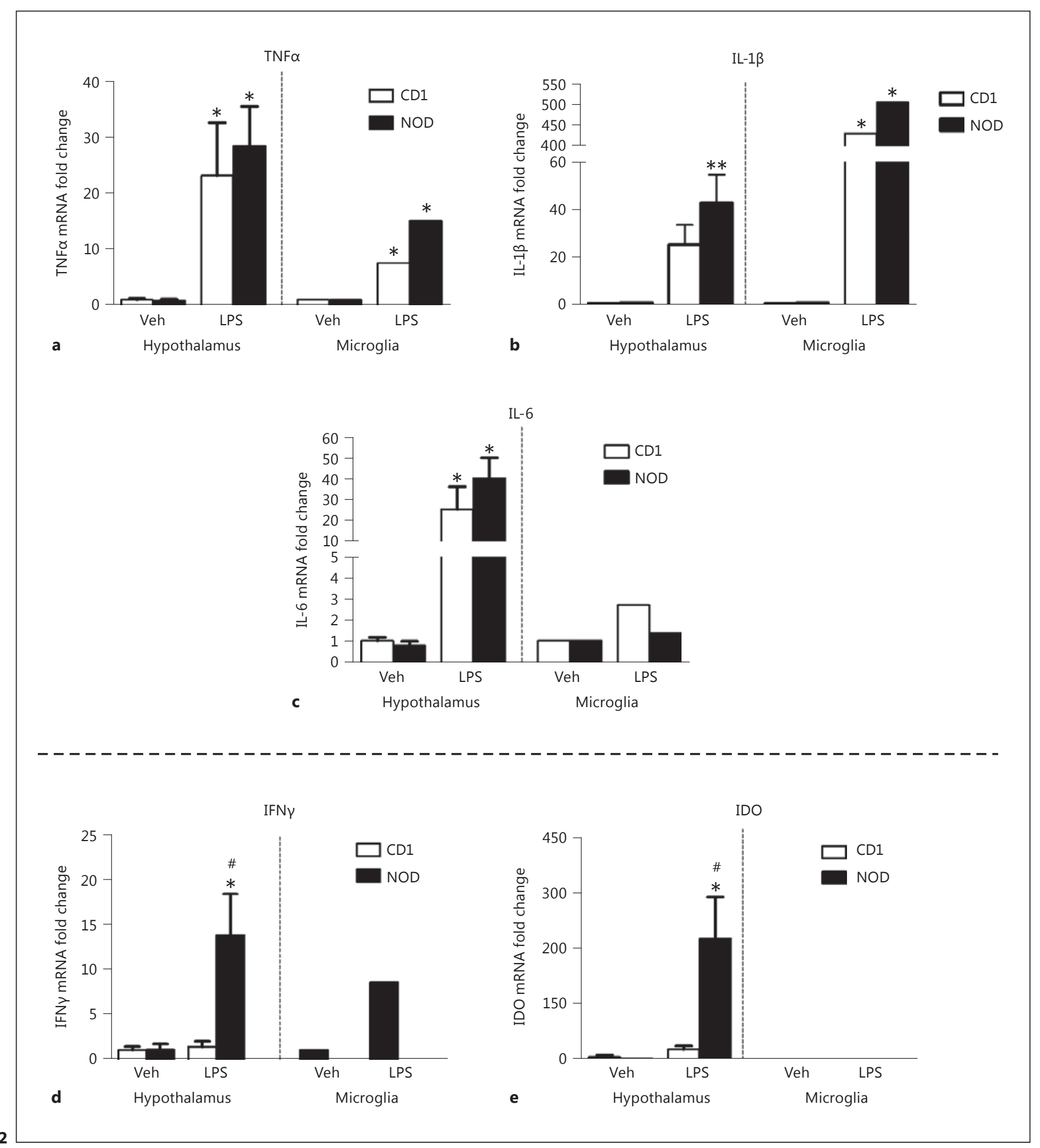

(For legend see next page.) 
ers CD40 and CD86 when compared to CD1 mice (table 1), supporting the view that immune cells are more activated in the NOD mouse brain than in the controls after LPS injection.

\section{Growth Factor Profile and Response to LPS}

Genes encoding the growth factors BDNF and PDGF were additionally analysed in the isolated microglia and hypothalamus of the NOD and CD1 mice. A significant effect of LPS, which differed per strain, was found when expression levels of BDNF and PDGF were measured in the hypothalamus. While no effect of LPS was found in the CD1 strain, a significant decrease in mRNA expression of both BDNF and PDGF was found in the NOD mouse at $4 \mathrm{~h}$ after LPS when compared to its relative control ( $\mathrm{p}<0.05$, fig. 3a, b). With regard to the microglia, no significant treatment effects were observed in either the NOD or CD 1 microglia in PDGF expression, but only the NOD microglia expressed BDNF.

\section{Behavioural Profiling of NOD Mice at Steady State}

In a first series of behavioural experiments, we tested various paradigms (open-field test, modified hole board, home cage activity monitoring and novelty-induced hy- pophagia) comparing NOD mice to 3 other strains, i.e. CD1, BALBc and C57BL/6 mice. Compared to the other strains, NOD mice were hyperactive in a novel situation: in the open-field and modified hole board tests, their activity was markedly increased (fig. 4a, b). Interestingly, we did not find marked differences in activity during longterm home cage observation (fig. 4c). This set of experiments suggests that NOD mice are hyper-reactive to novel situations rather than hyper-active.

In terms of the consumption of sweetened solutions (hedonia-related behaviour) the NOD mice did not markedly differ from the other strains (data not shown). Data obtained in the novelty-induced hypophagia test might have reflected an augmented anxiety-related behaviour in the NOD mice compared to in the CD1 and $\mathrm{Balb} / \mathrm{c}$ mice in this paradigm (fig. $4 \mathrm{~d}$ ). In the forced-swim test, passive stress-coping (commonly interpreted as depression-like behaviour) was least in the NOD mice during a first exposure in this paradigm (fig. 4e). Thus, comparable to the test paradigms of unconditioned anxiety, in the novel situation of the first forced-swim test, the NOD mice were very active. However, they displayed the strongest increase in passive stress-coping in a second forced-swim test conducted $24 \mathrm{~h}$ after the first one. This

Table 1. Microglial activation markers CD40 and CD86 in NOD and CD1 mice after LPS stimulation

\begin{tabular}{|c|c|c|c|c|c|c|}
\hline \multirow[t]{2}{*}{ Gene } & \multicolumn{2}{|l|}{ Control } & \multicolumn{2}{|c|}{$4 \mathrm{~h}$ after LPS } & \multicolumn{2}{|c|}{$24 \mathrm{~h}$ after LPS } \\
\hline & $\mathrm{CD} 1$ & NOD & $\mathrm{CD} 1$ & NOD & $\mathrm{CD} 1$ & NOD \\
\hline CD40 & $1 \pm 0.06$ & $0.8 \pm 0.04$ & $3.1 \pm 0.5^{*}$ & $5.8 \pm 0.5^{*}$ & $1.2 \pm 0.1$ & $0.86 \pm 0.03$ \\
\hline CD86 & $1 \pm 0.07$ & $1.1 \pm 0.04$ & $2.9 \pm 0.43^{*}$ & $4.7 \pm 0.13^{*}$ & $1.7 \pm 0.11$ & $01.8 \pm 0.1$ \\
\hline
\end{tabular}

Data expressed as mean \pm SEM, $n=5-6$ per group. These immune activation markers were found to be increased $4 \mathrm{~h}$ after LPS administration in the whole-brain tissue of both NOD and CD1 mice. NOD mice were found to have a significantly higher increase in both markers when compared to CD1 mice. ${ }^{*} \mathrm{p}<0.05$, LPS vs. control, with underlined values indicating where the values were significantly greater in NOD mice than in CD1 mice at the same time point $(\mathrm{p}<0.05)$.

Fig. 2. Investigation of mRNA expression of inflammatory markers in whole-brain tissue and isolated microglia. For whole-brain tissue, qPCR was used and data could be expressed as mean \pm SEM (bars), $\mathrm{n}=4-6$ per group. ${ }^{*} \mathrm{p}<0.05$, LPS vs. control. ${ }^{*} \mathrm{p}<0.05$, NOD vs CD1. For microglia, Affymetrix analysis data are given of 1 single experiment with pooled microglia. Four hours after LPS administration, significant increases in whole-brain tissue mRNA and microglial expression of TNFa (a), IL-1 $\beta$ (b) and IL-6 (c) were reported in both NOD and CD1 mice. No obvious differences between the NOD and CD1 mice were evident, although NOD always scored slightly higher. Microglial expression followed these patterns by and large, although IL-6 did not show significant increases. Investigation of mRNA expression of IFN $\gamma$ (d) and IDO (e) in whole-brain tissue revealed a significantly elevated expression in NOD mice following LPS administration when compared to vehicle-treated controls (Veh). These increases were also significantly greater than expression in the CD1 strain following LPS. Investigation of isolated microglia revealed expression of IFN $\gamma$ that was up-regulated after LPS only in NOD mice. A primer for IDO was not present on the microarray chip used in this study, so no information was available for isolated microglia. 
suggests that NOD mice developed a different strategy in the forced-swim test that could be interpreted as an increased development of behavioural despair.

In a second series of experiments conducted in another laboratory (Trinity instead of Affectis), investigation of the previously observed hyper-reactive phenotype did not reveal the same traits when comparing NOD to CD1 mice. The open-field test did not reveal any difference in total distance between strains [distance moved in the open field, NOD: mean 5,634 cm (SD 2,389) and CD1: mean $5,910 \mathrm{~cm}(\mathrm{SD} 1,831)]$. However, NOD mice displayed anxiety at steady state in the open-field arena [reduced distance in inner zone, NOD: mean 1,582 cm (SD 444) and CD1: mean 1,884 cm (SD 479)] and elevated plus maze [more time spent in covered arms, NOD: mean $167 \mathrm{~s}$ (SD 37) and CD1: mean $109 \mathrm{~s}$ (SD 18)] and a depressive-like phenotype in the TST [a greater time spent immobile, i.e. NOD $(\mathrm{n}=11)$ : mean time spent immobile $143 \mathrm{~s}(\mathrm{SEM}=9.08)$ and CD1 $(\mathrm{n}=12)$ : mean time spent immobile $102 \mathrm{~s}$; SEM $=8.05)$ at steady state].

NOD Mice Have a Greater Increase in Weight Loss at 24 Hours after LPS Injection and Display Exaggerated and Prolonged LPS-Induced Sickness Behaviour in the Home Cage

Since LPS induced a stronger inflammatory response (IL- $1 \beta$ and IFN $\gamma$ ) in the brain of NOD mice, we also studied weight loss and sickness behaviour in the NOD mouse versus the CD1 mouse. To determine any differential behavioural response to LPS in the NOD mouse, activity and rearing were monitored in the home cage activity paradigm. A significant effect of both strain and LPS were found when the activity of the mice was measured. While both CD1 and NOD showed comparable home cage ac-
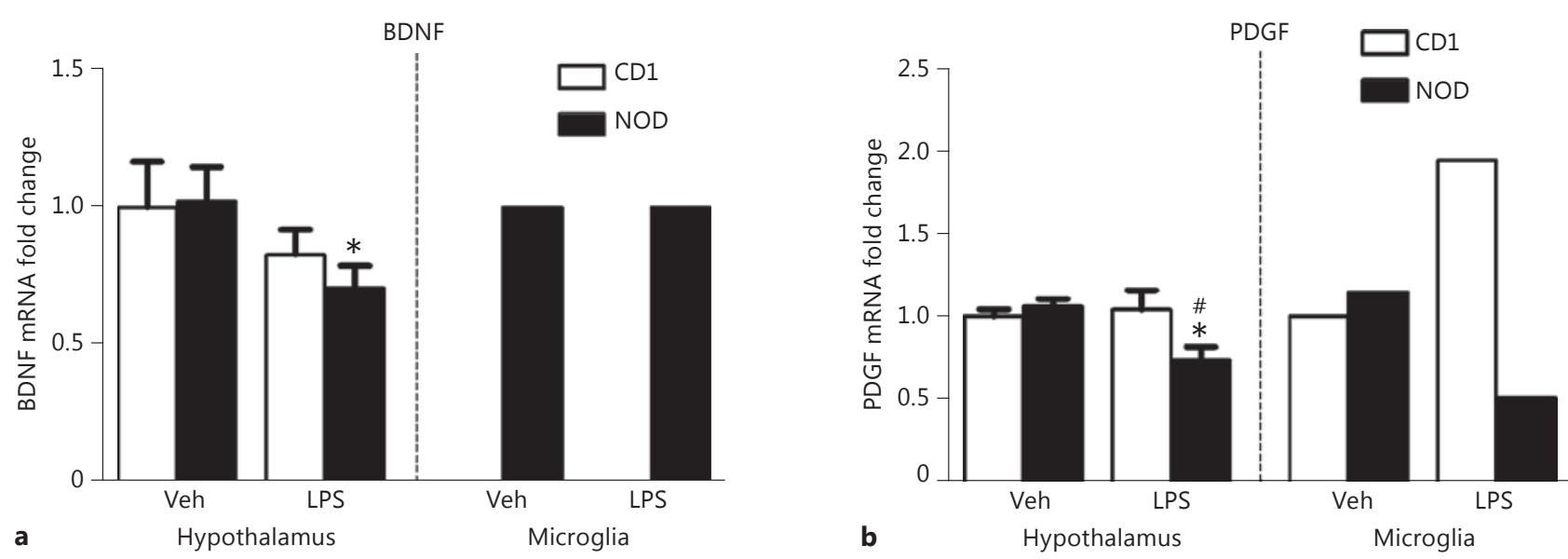

Fig. 3. Investigation of mRNA expression of growth factors in whole-brain tissue and isolated microglia. For whole-brain tissue, qPCR was used and data could be expressed as mean \pm SEM (bars), $\mathrm{n}=4-6$ per group. ${ }^{*} \mathrm{p}<0.05$, LPS vs. control. ${ }^{*} \mathrm{p}<0.05$, NOD vs. CD1. For microglia, Affymetrix analysis data are given of 1 single experiment with pooled microglia. Investigation of mRNA expres-

sion of growth factors in whole-brain tissue revealed different responses to LPS in the NOD and CD1 mice. NOD mice had a significantly reduced expression of $\operatorname{BDNF}(\mathbf{a})$ and $\operatorname{PDGF}(\mathbf{b})$ in whole-brain tissue following LPS administration. By and large, microglial expression followed this pattern for PDGF. Veh $=$ Vehicletreated control.

Fig. 4. Behaviour of male NOD (filled bars) in comparison to male $\mathrm{CD} 1, \mathrm{Balb} / \mathrm{C}$ and BL6 mice (all open bars) in various paradigms under novel and home cage conditions in the absence of LPS stimulation. NOD mice showed the highest activity in novel situations such as the open-field (a) and modified hole board (b) tests. $\mathbf{c}$ This hyper-activity was not present in the home cage environment. NOD mice had a shorter immobility time during initial exposure to the forced-swim test (FST1, d); however, when re-exposed to the FST $24 \mathrm{~h}$ later (FST2), the change in the passive stress-coping strat- egy (i.e. the time immobile in FST2 minus that in FST1) was highest in the NOD mice (e). $\mathbf{f}$ In the novelty-induced hypophagia test, an anxiety test independent of locomotor behaviour, NOD mice showed the highest latency to consume palatable liquid (i.e. latency in novel cage minus latency in home cage). $\mathbf{g}$ During the series of testing of basal behaviour, all NOD mice were in a pre-diabetic state as shown by the glucose levels determined in the blood drawn after the last test. Data are expressed as mean \pm SEM, $n=10 /$ strain; ${ }^{*} \mathrm{p}<0.05,{ }^{* *} \mathrm{p}<0.01,{ }^{* * *} \mathrm{p}>0.001$.

(For figure see next page.) DOI: $10.1159 / 000446370$
McGuiness/Gibney/Beumer/Versnel/ Sillaber/Harkin/Drexhage 


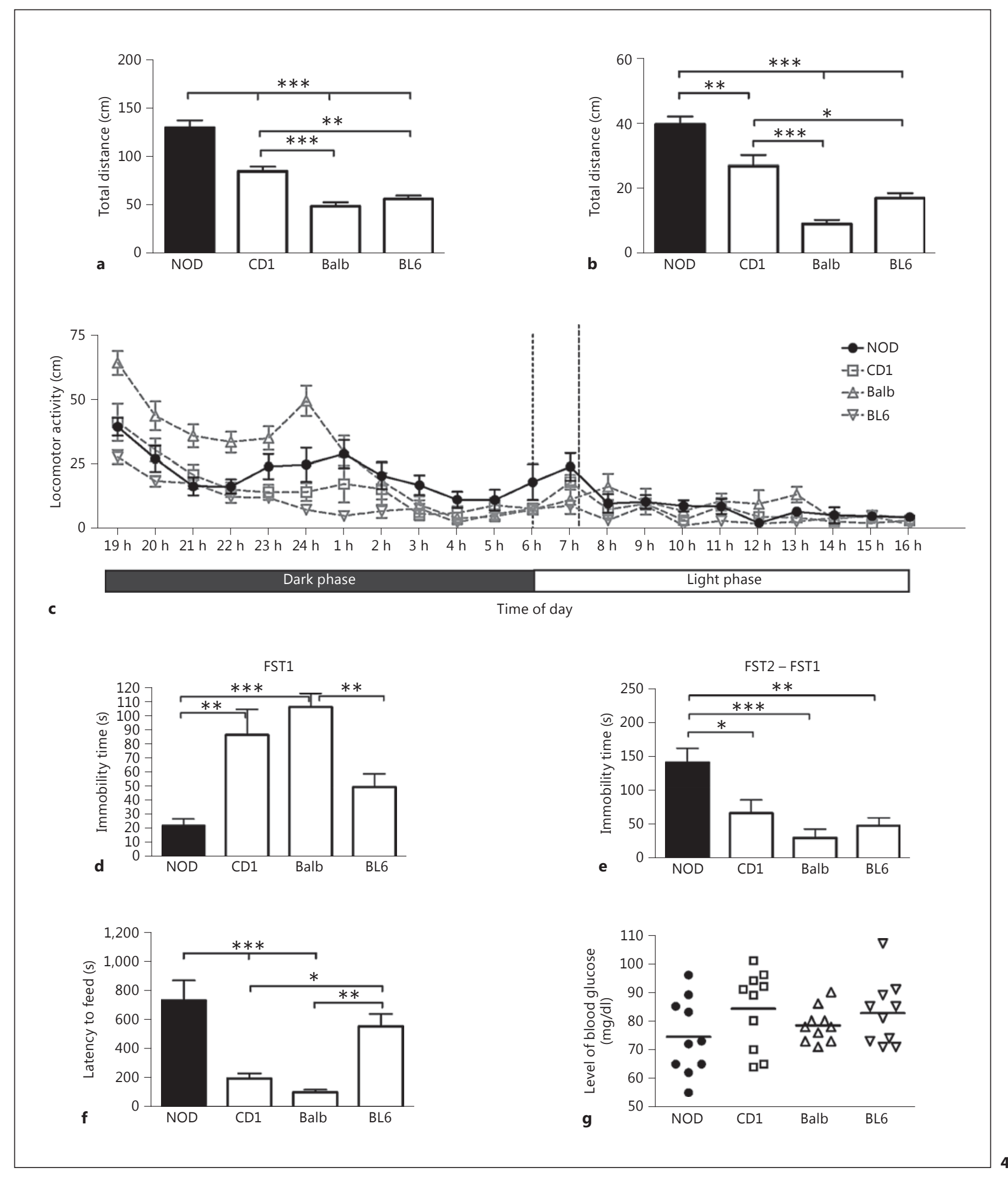

Excessive Responsiveness to LPS in the 


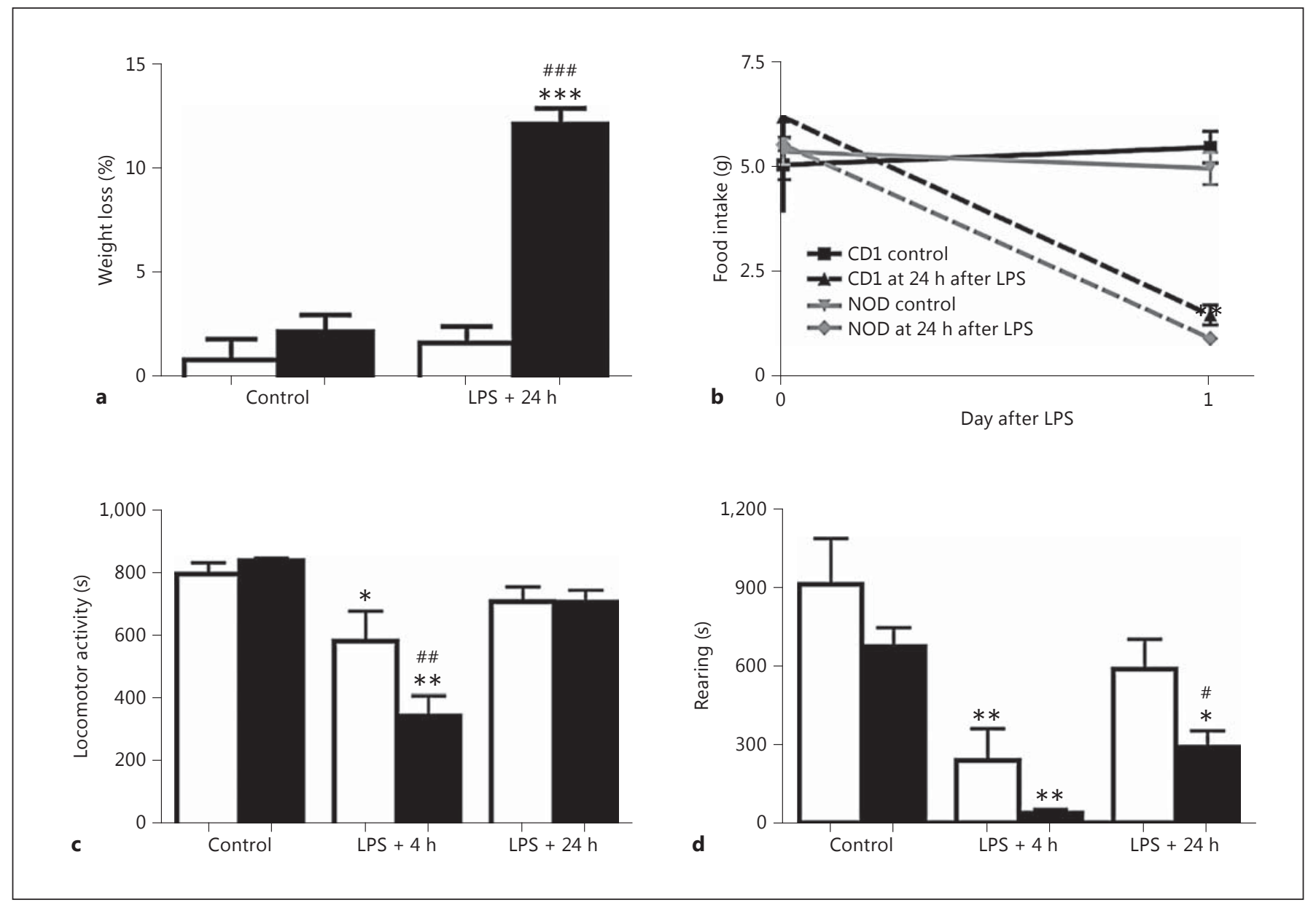

Fig. 5. Comparison of NOD (filled bars) with CD1 mice (open bars) in various paradigms after LPS or saline (control) i.p. injection. In response to LPS, NOD mice showed an exaggerated and prolonged behavioural response to LPS stimulation as indicated by a strong reduction in body weight $24 \mathrm{~h}$ after LPS (a) which was independent of food intake (b), a more pronounced reduction in home cage activity $4 \mathrm{~h}$ after LPS (c) and a reduction in rearing that was maintained for at $24 \mathrm{~h}$ after LPS (d). Data expressed as mean \pm SEM, $\mathrm{n}=5-6$ per group. ${ }^{* * *} \mathrm{p}<0.001,{ }^{* *} \mathrm{p}<0.01,{ }^{*} \mathrm{p}<0.05$, LPS vs. control. ${ }^{\# \#} \mathrm{p}<0.001,{ }^{\# \#} \mathrm{p}<0.01,{ }^{\#} \mathrm{p}<0.05$, NOD vs. CD1. tivity at steady state and they both showed reduced activity at $4 \mathrm{~h}$ after LPS administration when compared to their respective controls $(\mathrm{p}<0.05$ and $\mathrm{p}<0.01$, respectively), this altered behaviour was more pronounced in the NOD mice, with activity significantly reduced at $4 \mathrm{~h}$ after LPS when compared to the CD1 mice at the same time point $(\mathrm{p}<0.01$; fig. $5 \mathrm{c})$. Similarly, an effect of strain and LPS on rearing behaviour in this paradigm was also apparent. Once again, no difference was found in the behaviour of the 2 strains at steady state. Furthermore, both strains showed comparable reductions in rearing $4 \mathrm{~h}$ after LPS relative to their controls ( $\mathrm{p}<0.01)$. However, at $24 \mathrm{~h}$, while rearing in the CD1 mouse had returned to control levels, it was still significantly reduced in the NOD mouse
( $p<0.05$ ), suggesting a prolonged behavioural response to LPS (fig. 5d).

Furthermore, when body weight was recorded at baseline and then subsequently at $24 \mathrm{~h}$ after injection, a significant effect of both strain and LPS were found. Posthoc analysis revealed that while no difference in body weight was observed in the CD1 strain, a significant increase in weight loss was found in NOD mice $24 \mathrm{~h}$ after LPS when compared to saline-treated controls ( $p<0.01$, fig. 5a). This was independent of strain differences in food intake after LPS, where both CD1 and NOD mice showed comparable, significant decreases in food intake $24 \mathrm{~h}$ after LPS (fig. 5b). 
Table 2. Previously published results on NOD behaviour at steady state

\begin{tabular}{|c|c|c|c|}
\hline $\begin{array}{l}\text { First author } \\
\text { [ref.] }\end{array}$ & Compared mouse strains & Behaviour & Activity \\
\hline Moy [61] & $\begin{array}{l}\text { AKR/J, C57BL/6J, C58/J, DBA/2J, VB/NJ, NOD/ } \\
\text { LtJ, NZB/BINJ, PERA/EiJ, PL/J, SJL/J, SWR/J }\end{array}$ & $\begin{array}{l}\text { open-field test } \\
\text { elevated plus maze } \\
\text { sociability and preference } \\
\text { for social novelty }\end{array}$ & $\begin{array}{l}\uparrow \\
\uparrow \\
=\end{array} \quad$ (highest total arm entries) \\
\hline Amrani [19] & C57BL/6 (male and female) & open-field test & $\uparrow$ \\
\hline
\end{tabular}

These reports show that NOD mice display a hyper-active phenotype when exposed to a novel environment.

\section{Discussion}

Our study has a number of limitations. First of all, the experiments on isolated microglia are limited to only Affymetrix analyses. The reason is the paucity of cells obtained in the relatively laborious and difficult procedure for microglial isolation. We were therefore unable to perform confirmative qPCR on isolated microglia, but we did perform parallel qPCR studies on whole-brain (hypothalamus) tissue.

Behavioural studies were carried out in 2 series of experiments in different laboratories, using, in one instance, 3 contrast strains but only 1 (the parental CD1 strain) in the other . Furthermore, owing to multiple experimental locations and difficulty sourcing mice from the same company, behavioural research was carried out on mice from different sources, meaning that they cannot be considered to have undergone exactly the same treatment prior to testing between different groups. At Affectis, behavioural profiling was conducted on male mice, while the rest of the experiments were conducted using female mice. This was done for economic reasons. Despite our best efforts to minimise any potential variations, differences in delivery stress, housing conditions, diet and gut microbiota could exist. Thus, from our behavioural experiments, definite conclusions on NOD behaviour are difficult to draw and so we will only draw limited conclusions in relation to the existing literature; experiments knocking in or out important microglial inflammatory genes (like IFN $\gamma$ and IL-1) in the NOD strain would be further steps to unravel immune-related behaviour in this autoimmune strain.

Excessive Responsiveness to LPS in the Brain of NOD Mice
Despite the limitations of the study, we are confident that it shows that the Affymetrix genome profile and the BrdU incorporation of NOD mouse microglia point to a relatively high proliferation rate under steady state conditions. In addition, $24 \mathrm{~h}$ after LPS injection, Affymetrix genome analysis still indicated that the parameters cell cycle and DNA replication were the most affected functions (see online suppl. table 1). Interestingly, a high proliferation rate, similarly high to microglia, was found for the myeloid population in the pancreas of the NOD mouse, which has, again similar to the microglia, its own precursor cell population in its local micro-environment $[8,10]$.

Signs of a high pro-inflammatory set point of microglia and brain of the steady state NOD mouse could not be detected, refuting the idea that this mouse is a model for mood disorders based on a spontaneous high inflammatory set point of its microglia/brain tissue. Indeed, in our behaviour experiments (carried out at locations under different conditions), we did not find consistent signs of depressive behaviour of the steady state NOD mouse. However, the behavioural experiments did reveal that the steady state NOD mouse was hyper-reactive to novel environments in 1 series of experiments (Affectis) with some signs of anxiety-related behaviour (novelty-induced hypophagia test) and an increased development of behavioural despair (second forced-swim test), while the other series of experiments showed more anxious behaviour in the open-field and elevated plus maze paradigm (Trinity). Hyper-reactive behaviour of the NOD mouse to novel environments has been noticed before by 3 independent investigators comparing the NOD mouse to a series of control strains (table 2). Although our data are thus inconsis-

Neuroimmunomodulation 2016;23:137-150 
tent, we believe (with regard for the literature data) that it is likely that the NOD mouse displays hyper-reactive behaviour to novel environments (with some signs of anxiety and despair), but further detailed studies are required. These experiments should also take into account whether this behaviour is linked to the high proliferation rate of NOD microglia because such a link cannot be deduced from our series of experiments.

For the pancreas, we have shown that the aberrant proliferation of the local myeloid population leads to a higher sensitivity of the progeny cells to LPS reacting with a heightened production of pro-inflammatory cytokines [10]. We report here that the microglia and hypothalamus of the NOD mouse shows an exaggerated immune activation and inflammatory response to systemic LPS injection. Expression of CD40 and CD86 were enhanced in the NOD mouse hypothalamus compared to the CD1 mouse $4 \mathrm{~h}$ after LPS exposure. CD40 is an important regulator of the activation of microglia and macrophages and serves as an amplifier of pro-inflammatory responses in the central nervous system [42]. CD86 is an activation marker of myeloid cells and has been reported to be present in activated microglia [43]. Although LPS-induced expression of the pro-inflammatory cytokines TNFa and IL-6 did not differ between strains, expression of IL- $1 \beta$ was significantly enhanced in the NOD mouse wholebrain tissue in response to LPS (and not in CD1 mice). With regard to the purified microglia, stronger increases of IL- $1 \beta$ to LPS were noted in the whole-genome analyses (although not reaching statistical significance). Clearest, however, was a very robust LPS-induced increase in IFN $\gamma$ expression in the NOD brain when compared to the CD1 brain, further supporting a heightened brain inflammatory response of the NOD mouse to LPS stimulation. Again, the purified microglia showed a heightened IFN $\gamma$ response to LPS (not significantly different between strains). IFN $\gamma$ is one of the most potent inducers of the kynurenine pathway enzyme, IDO [44, 45]. Accordingly, a large increase in the expression of IDO was found in the NOD hypothalamus $4 \mathrm{~h}$ after LPS stimulation, and remained elevated at $24 \mathrm{~h}$. It has been hypothesised that the delayed depressive behaviour observed in animal models that occurs after the initial sickness behaviour induced by LPS may be due to IDO and kynurenine pathway activation [46]. This is supported by the fact that LPS-induced depressive behaviour can be blocked by the pharmacological inhibition of IDO [47].

Indeed, in our experiments, the NOD mouse showed delayed and exaggerated sickness behaviour when exposed to LPS, as indicated by excessive weight loss and an exaggerated reduction in rearing activity in the home cage. Rearing is considered a measure of exploratory behaviour and reduced exploration can be indicative of anxiety in animals $[48,49]$. Our findings are in agreement with previous studies in which an excessive sickness- and altered anxiety-behavioural phenotype was found when NOD mice were exposed to an immune stimulus $[19,20]$. We therefore conclude that it is likely that the NOD mouse response to LPS stimulation is one of heightened brain inflammation and increased sickness behaviour. However, further experiments (e.g. blocking inflammation with anti-inflammatory drugs) are needed to causally link the 2 phenomena.

Not only was there an excessive inflammatory response to LPS stimulation, there was also an indication of a relative deficiency of 2 growth factor responses in the NOD mouse brain. For PDGF, stronger decreases in levels were found in whole-brain tissue and microglia of NOD mice in response to LPS. PDGF is an important growth factor for neuronal stem cells in the hypothalamus and mediates neurite outgrowth [50].

BDNF in the whole-brain tissue of NOD mice showed a stronger and significant decrease in response to LPS in comparison to a decrease in the CD1 mice; however, this decrease could not be observed in the case of the microglia. BDNF is a well-known growth factor for neuronal cells and a deficiency of BDNF has been suggested as an important factor in the development of mood disorders in both preclinical [51-53] and clinical [54] reports. Moreover, a decrease in the level of BDNF in the brain due to inflammatory stimulation is a well-known phenomenon, with IL-1 $\beta[55]$ and LPS $[31,56]$ previously reported as reducing BDNF expression in the rodent brain. We conclude that the sensitivity of the NOD mouse for immune stimulation extends to inflammation-induced decreases in neuronal growth factors. Interestingly, the NOD mouse has indeed been shown to have impaired neurogenesis and reduced neuronal survival [5760].

In conclusion, despite study limitations, our data demonstrate that, in response to LPS stimulation, prediabetic NOD mice show a high microglia proliferation rate, an increased brain inflammatory response, a relative deficiency in PDGF and BDNF, increased weight loss and prolonged sickness behaviour. The NOD mouse is therefore an interesting model for further study of the relationship between an aberrant immune system, autoimmunity and abnormal behaviour, with more emphasis on the relevant brain regions like the hypothalamus and amygdala. 


\section{Acknowledgements}

The authors would like to acknowledge grant support from the EUFP7 MOODINFLAME and PSYCHAID Consortia.

\section{Disclosure Statement}

The authors declare no conflicts of interest.

\section{References}

1 Chaparro RJ, Dilorenzo TP: An update on the use of NOD mice to study autoimmune (type 1) diabetes. Expert Rev Clin Immunol 2010;6: 939-955.

2 Homo-Delarche F: Neuroendocrine immuno-ontogeny of the pathogenesis of autoimmune disease in the nonobese diabetic (NOD) mouse. ILAR J 2004;45:237-258.

-3 Nikolic T, Bunk M, Drexhage HA, Leenen PJ: Bone marrow precursors of nonobese diabetic mice develop into defective macrophagelike dendritic cells in vitro. J Immunol 2004 173:4342-4351.

-4 Strid J, Lopes L, Marcinkiewicz J, Petrovska L, Nowak B, Chain BM, Lund T: A defect in bone marrow derived dendritic cell maturation in the nonobese diabetic mouse. Clin Exp Immunol 2001;123:375-381.

5 Charre S, Rosmalen JG, Pelegri C, Alves V, Leenen PJ, Drexhage HA, Homo-Delarche F: Abnormalities in dendritic cell and macrophage accumulation in the pancreas of nonobese diabetic (NOD) mice during the early neonatal period. Histol Histopathol 2002;17: 393-401.

6 Homo-Delarche F, Drexhage HA: Immune cells, pancreas development, regeneration and type 1 diabetes. Trends Immunol 2004; 25:222-229.

7 Diana J, Simoni Y, Furio L, Beaudoin L, Agerberth $B$, Barrat F, Lehuen A: Crosstalk between neutrophils, B-1a cells and plasmacytoid dendritic cells initiates autoimmune diabetes. Nat Med 2013;19:65-73.

8 Welzen-Coppens JM, Van Helden-Meeuwsen CG, Drexhage HA, Versnel MA: Abnormalities of dendritic cell precursors in the pancreas of the NOD mouse model of diabetes. Eur J Immunol 2012;42:186-194.

$\checkmark 9$ Anderson MS, Bluestone JA: The NOD mouse: a model of immune dysregulation. Annu Rev Immunol 2005;23:447-485.

10 Beumer W, Welzen-Coppens JMC, Van Helden-Meeuwsen CG, Gibney SM, Drexhage HA, Versnel MA: The gene expression profile of $\mathrm{CD} 11 \mathrm{c}(+) \mathrm{CD} 8$ alpha(-) dendritic cells in the pre-diabetic pancreas of the NOD mouse. PLoS One 2014;9:e103404.

-11 Ridgway WM, Fasso M, Lanctot A, Garvey C, Fathman CG: Breaking self-tolerance in nonobese diabetic mice. J Exp Med 1996;183: 1657-1662.

-12 Stoffels K, Overbergh L, Giulietti A, Kasran A, Bouillon R, Gysemans C, Mathieu C: NOD macrophages produce high levels of inflammatory cytokines upon encounter of apoptotic or necrotic cells. J Autoimmun 2004;23:9-15.
13 Benros ME, Waltoft BL, Nordentoft M, Ostergaard SD, Eaton WW, Krogh J, Mortensen PB: Autoimmune diseases and severe infections as risk factors for mood disorders. A nationwide study. JAMA Psychiatry 2013;70: 812-820.

14 Eaton WW, Byrne M, Ewald H, Mors O, Chen C-Y, Agerbo E, Mortensen PB: Association of schizophrenia and autoimmune diseases: linkage of Danish National Registers. Am J Psychiatry 2006;163:521-528.

15 Kupka RW, Nolen WA, Post RM, Mcelroy SL, Altshuler LL, Denicoff KD, Frye MA, Keck PE, Leverich GS, Rush AJ, Suppes T, Pollio C, Drexhage HA: High rate of autoimmune thyroiditis in bipolar disorder: lack of association with lithium exposure. Biol Psychiatry 2002; 51:305-311

16 Hillegers MHJ, Reichart CG, Wals M, Verhulst FC, Ormel J, Nolen WA, Drexhage HA: Signs of a higher prevalence of autoimmune thyroiditis in female offspring of bipolar parents. Eur Neuropsychopharmacol 2007;17: 394-399.

17 Vonk R, Van Der Schot AC, Kahn RS, Nolen WA, Drexhage HA: Is autoimmune thyroiditis part of the genetic vulnerability (or an endophenotype) for bipolar disorder? Biol Psychiatry 2007;62:135-140.

18 Bergink V, Burgerhout KM, Weigelt K, Pop VJ, De Wit H, Drexhage RC, Kushner SA, Drexhage HA: Immune system dysregulation in first-onset postpartum psychosis. Biol Psychiatry 73:1000-7, 2013.

19 Amrani A, Chaouloff F, Mormede P, Dardenne M, Homo-Delarche F: Glucose, insulin, and open field responses to immobilization in nonobese diabetic (NOD) mice. Physiol Behav 1994;56:241-246.

20 Bluth, Jafarian-Tehrani M, Michaud B, Haour F, Dantzer R, Homo-Delarche F: Increased sensitivity of prediabetic nonobese diabetic mouse to the behavioral effects of IL-1. Brain Behav Immun 1999;13:303-314.

21 Gibney SM, Drexhage HA: Evidence for a dysregulated immune system in the etiology of psychiatric disorders. J Neuroimmune Pharmacol 2013;8:900-920.

22 Beumer W, Gibney SM, Drexhage RC, PontLezica L, Doorduin J, Klein HC, Steiner J, Connor TJ, Harkin A, Versnel MA, Drexhage HA: The immune theory of psychiatric diseases: a key role for activated microglia and circulating monocytes. J Leukoc Biol 2012;92: 959-975.
23 Bergink V, Kushner SA, Pop V, Kuijpens H, Lambregtse-Van Den Berg MP, Drexhage RC, Wiersinga W, Nolen WA, Drexhage, HA: Prevalence of autoimmune thyroid dysfunction in postpartum psychosis. Br J Psychiatry 2011;198:264-268.

24 Drexhage RC, Hoogenboezem TH, Versnel MA, Berghout A, Nolen WA, Drexhage HA: The activation of monocyte and $\mathrm{T}$ cell networks in patients with bipolar disorder. Brain Behav Immun 2011;25:1206-1213.

25 Haarman BCM, Riemersma-Van Der Lek RF, Burger H, Netkova M, Drexhage RC, Bootsman F, Mesman E, Hillegers MHJ, Spijker AT, Hoencamp E, Drexhage HA, Nolen WA: Relationship between clinical features and inflammation-related monocyte gene expression in bipolar disorder - towards a better understanding of psychoimmunological interactions. Bipolar Disord 2014;16:137-150.

26 Irwin MR: Human psychoneuroimmunology: 20 years of discovery. Brain Behav Immun 2008;22:129-139.

27 Pace TW, Hu F, Miller AH: Cytokine-effects on glucocorticoid receptor function: relevance to glucocorticoid resistance and the pathophysiology and treatment of major depression. Brain Behav Immun 2007;21:9-19.

28 Dunn AJ: Effects of cytokines and infections on brain neurochemistry. Clin Neurosci Res 2007;6:52-68.

29 Dantzer R, O'Connor JC, Freund GG, Johnson RW, Kelley KW: From inflammation to sickness and depression: when the immune system subjugates the brain. Nat Rev Neurosci 2008;9:46-56.

30 Dobos N, De Vries EF, Kema IP, Patas K, Prins M, Nijholt IM, Dierckx RA, Korf J, Den Boer JA, Luiten PG, Eisel UL: The role of indoleamine 2,3-dioxygenase in a mouse model of neuroinflammation-induced depression. J Alzheimers Dis 2012;28:905-915.

31 Guan Z, Fang J: Peripheral immune activation by lipopolysaccharide decreases neurotrophins in the cortex and hippocampus in rats. Brain Behav Immun 2006;20:64-71.

- 32 Tanaka S, Ide M, Shibutani T, Ohtaki H, Numazawa S, Shioda S, Yoshida T: Lipopolysaccharide-induced microglial activation induces learning and memory deficits without neuronal cell death in rats. $J$ Neurosci Res 2006;83:557-566.

33 Pont-Lezica L, Beumer W, Colasse S, Drexhage $\mathrm{H}$, Versnel M, Bessis A: Microglia shape corpus callosum axon tract fasciculation: functional impact of prenatal inflammation. Eur J Neurosci 2014;39:1551-1557. 
-34 Dickerson F, Schroeder J, Stallings C, Origoni A, Bahn S, Yolken R: Multianalyte markers of schizophrenia and bipolar disorder: a preliminary study. Schizophr Res 2015;168:450455.

35 Beumer W, Effraimidis G, Drexhage RC, Wiersinga WM, Drexhage HA: Changes in serum adhesion molecules, chemokines, cytokines, and tissue remodeling factors in euthyroid women without thyroid antibodies who are at risk for autoimmune thyroid disease: a hypothesis on the early phases of the endocrine autoimmune reaction. J Clin Endocrinol Metabol 2013;98:2460-2468.

- 36 Mesman E, Hillegers MH, Ambree O, Arolt V, Nolen WA, Drexhage HA: Monocyte activation, brain-derived neurotrophic factor (BDNF), and S100B in bipolar offspring: a follow-up study from adolescence into adulthood. Bipolar Disord 2015.;17:39-49.

37 De Haas AH, Boddeke HW, Biber K: Regionspecific expression of immunoregulatory proteins on microglia in the healthy CNS. Glia 2008;56:888-894.

38 Bolstad BM, Irizarry RA, Astrand M, Speed TP: A comparison of normalization methods for high density oligonucleotide array data based on variance and bias. Bioinformatics 2003;19:185-193.

- 39 Boyle NT, Connor TJ: MDMA ('Ecstasy') suppresses the innate IFN-gamma response in vivo: a critical role for the anti-inflammatory cytokine IL-10. Eur J Pharmacol 2007; 572:228-238.

-40 Sillaber I, Panhuysen M, Henniger MS, Ohl F, Kuhne C, Putz B, Pohl T, Deussing JM, PaezPereda M, Holsboer F: Profiling of behavioral changes and hippocampal gene expression in mice chronically treated with the SSRI paroxetine. Psychopharmacology 2008;200:557572.

-41 Schweizer MC, Henniger MS, Sillaber I: Chronic mild stress (CMS) in mice: of anhedonia, 'anomalous anxiolysis' and activity. PLoS One 2009;4:e4326.

-42 Benveniste EN, Nguyen VT, Wesemann DR: Molecular regulation of $\mathrm{CD} 40$ gene expression in macrophages and microglia. Brain Behav Immun 2004;18:7-12.

43 Ponomarev ED, Shriver LP, Maresz K, Dittel BN: Microglial cell activation and proliferation precedes the onset of CNS autoimmunity. J Neurosci Res 2005;81:374-389.
44 Leonard BE: Inflammation, depression and dementia: are they connected? Neurochem Res 2007;32:1749-1756.

45 King NJ, Thomas SR: Molecules in focus: indoleamine 2,3-dioxygenase. Int J Biochem Cell Biol 2007;39:2167-2172.

46 Dantzer R, O’Connor JC, Lawson MA, Kelley KW: Inflammation-associated depression: from serotonin to kynurenine. Psychoneuroendocrinology 2011;36:426-436.

47 O'Connor JC, Lawson MA, Andre C, Moreau M, Lestage J, Castanon N, Kelley KW, Dantzer R: Lipopolysaccharide-induced depressivelike behavior is mediated by indoleamine 2,3-dioxygenase activation in mice. Mol Psychiatry 2009;14:511-522.

48 Cryan JF, Holmes A: The ascent of mouse: advances in modelling human depression and anxiety. Nat Rev Drug Discov 2005;4:775790.

49 Bailey KR, Crawley JN: Anxiety-related behaviors in mice; in Buccafusco JJ (ed): Methods of Behavior Analysis in Neuroscience, ed 2. Boca Raton, CRC Press/Taylor \& Francis, 2009, chapt 5

50 Son GH, Geum D, Jung H, Kim K: Glucocorticoid inhibits growth factor-induced differentiation of hippocampal progenitor HiB5 cells. J Neurochem 2001;79:1013-1021.

51 Molteni R, Calabres, F, Chourbaji S, Brandwein C, Racagni G, Gass P, Riva MA: Depression-prone mice with reduced glucocorticoid receptor expression display an altered stressdependent regulation of brain-derived neurotrophic factor and activity-regulated cytoskeleton-associated protein. J Psychopharmacol 2010;24:595-603

52 Calabrese F, Molteni R, Cattaneo A, Macchi F, Racagni G, Gennarelli M, Ellenbroek BA, Riva MA: Long-Term duloxetine treatment normalizes altered brain-derived neurotrophic factor expression in serotonin transporter knockout rats through the modulation of specific neurotrophin isoforms. Mol Pharmacol 2010;77:846-853.

53 Chourbaji S, Hortnagl H, Molteni R, Riva MA, Gass P, Hellweg R: The impact of environmental enrichment on sex-specific neurochemical circuitries - effects on brain-derived neurotrophic factor and the serotonergic system. Neuroscience 2012:220:267-276.
54 Dwivedi Y, Rizavi HS, Conley RR, Roberts RC, Tamminga CA, Pandey GN: Altered gene expression of brain-derived neurotrophic factor and receptor tyrosine kinase B in postmortem brain of suicide subjects. Arch Gen Psychiatry 2003;60:804-815.

55 Lapchak PA, Araujo DM, Hefti F: Systemic interleukin-1 beta decreases brain-derived neurotrophic factor messenger RNA expression in the rat hippocampal formation. Neuroscience 1993;53:297-301.

56 Schnydrig S, Korner L, Landweer S, Ernst B, Walker G, Otten U, Kunz D: Peripheral lipopolysaccharide administration transiently af fects expression of brain-derived neurotrophic factor, corticotropin and proopiomelanocortin in mouse brain. Neurosci Lett 2007; 429:69-73.

57 Beauquis J, Homo-Delarche F, Revsin Y, De Nicola AF, Saravia F: Brain alterations in autoimmune and pharmacological models of diabetes mellitus: focus on hypothalamic-pituitary-adrenocortical axis disturbances. Neuroimmunomodulation 2008;15:61-67.

58 Beauquis J, Saravia F, Coulaud J, Roig P, Dardenne M, Homo-Delarche F, De Nicola A: Prominently decreased hippocampal neurogenesis in a spontaneous model of type 1 diabetes, the nonobese diabetic mouse. Exp Neurol 2008;210:359-367.

-59 Saravia FE, Gonzalez SL, Roig P, Alves V, Homo-Delarche F, De Nicola AF: Diabetes increases the expression of hypothalamic neuropeptides in a spontaneous model of type I diabetes, the nonobese diabetic (NOD) mouse. Cell Mol Neurobiol 2001;21:15-27.

-60 Saravia FE, Revsin Y, Gonzalez Deniselle MC, Gonzalez SL, Roig P, Lima A, Homo-Delarche F, De Nicola AF: Increased astrocyte reactivity in the hippocampus of murine models of type 1 diabetes: the nonobese diabetic (NOD) and streptozotocin-treated mice. Brain Res 2002;957:345-353.

61 Moy SS, Nadler JJ, Young NB, Nonneman RJ, Segall SK, Andrade GM, Crawley JN, Magnuson TR: Social approach and repetitive behavior in eleven inbred mouse strains. Behav Brain Res 2008;191:118-129.

62 Bothe GW, Bolivar VI, Vedder MJ, Geistfeld JG: Behavioral differences among fourteen inbred mouse strains commonly used as disease models. Comp Med 2005;55:326-334. 